\title{
FAKTOR YANG MEMPENGARUHI KEPUTUSAN MAHASISWA BARU MENEMPUH KULIAH DI STIE AAS DITINJAU DARI MARKETING MIX
}

\author{
Rukmini dan LMS Kristiyanti \\ STIE AAS Surakarta \\ Email : rukminidra@yahoo.co.id
}

\begin{abstract}
ABSTRAK
Obyek penelitian adalah mahasiswa baru STIE AAS tahun akademik 2015/2016 dengan sampel sebanyak 80 orang .Teknik pengumpulan data dengan Kuesioner, sedangkan Metode analisa data dengan uji instrument untuk menguji validitas dan reliebilitas. Untuk mengetahui pengaruh variabel program studi, biaya perkuliahan, lokasi kampus, media cetak, media elektronik dan personal selling terhadap keputusan mahasiswa menggunakan analisis Regresi berganda.Tujuan penelitian ini adalah untuk mengetahui apakah factor program studi, biaya perkuliahan, lokasi, media cetak, media elektronik dan personal selling mempunyai pengaruh terhadap keputusan mahasiswa baru dan untuk mengetahui apakah variabel variable bebas secara bersama sama mempengaruhi Keputusan mahasiswa baru menempuh kuliah di STIE AAS Surakarta. Hasil penelitian menunjukkan terdapat pengaruh positif dan signifikan antara variabel biaya perkuliahan, lokasi kampus, promosi media cetak, media elektronik dan personal seling terhadap keputusan menempuh kuliah di STIE AAS. Sedangkan variabel program studi tidak berpengaruh positif terhadap Keputusan Mahasiswa Uji F menunjukkan variabel variabel Marketing mix tersebut secara bersama sama terdapat pengaruh positif dan signifikan terhadap keputusan menempuh kuliah di STIE AAS. Sedangkan uji $t$ variabel program studi, biaya perkuliahan, lokasi kampus, media cetak, media elektronik dan personal selling dalam marketing mix tidak berpengaruh terhadap Keputusan Mahasiswa menempuh Kuliah di STIE AAS
\end{abstract}

Kata kunci : program studi, biaya perkuliahan, lokasi, promosi media cetak, media elektronik, personal selling, keputusan mahasiswa

\section{PENDAHULUAN}

Konsep Pemasaran bertujuan memberikan kepuasan terhadap keinginan dan kebutuhan konsumen. Hal tersebut secara prinsip berbeda dengan dengan falsafah bisnis terdahulu yang berorienrtasi pada produk dan penjualan. Pada konsep ini beranggapan bahwa orientasi dari konsep konsep tersebut bertolak dari produk perusahaan dan memandang hanya sebagai tugas perusahaan yaitu bagian penjualan dan bagian promosi untuk memberikan stimulasi volume penjualan yang menguntungkan.

Sedangkan pada konsep pemasaran bahwa kegiatan pemasaran suatu perusahaan harus dimulai dengan usaha mengenal dan merumuskan keinginan dan kebutuhan konsumen.

Kemudian perusahaan tersebut harus merumuskan keinginan dan menyusun suatu kombinasi dari perusahaan kebijakan produk, harga, promosi dan distribusi (marketing mix) setepat tepatnya 
agar kebutuhan para konsumennya dapat terpenuhi secara memuaskan, yang pada akhirnya konsumen yang puas akan menjadi asset bagi perusahaan untuk memajukan dan mengembangkan perusahaan.

Strategi Pemasaran bukanlah merupakan sejumlah tindakan khusus, tetapi lebih merupakan pernyataan yang menunjukkan usaha usaha pemasaran pokok yang dilakukan perusahaan, dan diarahkan untuk mencapai tujuan . Tujuan perusahaan yang menganut konsep pemasaran pada dasarnya adalah memberikan kepuasan kepada konsumen ( Handoko 2000). Sehingga perusahaan perlu menganalisis faktor apa saja yang mempengaruhi keputusan pembelian konsumen terhadap barang atau jasa. Hal ini penting dilakukan untuk mengukur keberhasilan perusahaan dalam memasarkan produk atau jasa yang dijual.

Marketing Mix merupakan unsur pokok dalam strategi pemasaran. Marketing mix merupakan variable variable terkontrol yang dapat dipergunakan perusahaan untuk mempengaruhi tanggapan konsumen dari suatu golongan atau segmen tertentu. Bila perusahaan ingin meraih pangsa pasar maka perusahaan tersebut harus merumuskan kombinasi aspek aspek strategi pemasaran tersebut yang terdiri dari produk, harga, distribusi dan promosi ( marketing mix ) dengan tepat dan mempergunakan teknik teknik pemasaran yang sesuai dengan perilaku konsumennya. Oleh karena itu perumusan strategi marketing mix sangat ditentukan oleh karakterisistik segmen pasarnya, yaitu menyangkut perilaku konsumen dan proses pembeliannya.
Semakin banyaknya persaingan di dunia usaha terhadap barang atau jasa sejenis, perusahaan harus pandai pandai menyikapi situasi. Apalagi di sektor jasa yang jauh lebih sulit mengenalkan pada pasar karena secara fisik tidak nampak wujudnya. Namun tidak sedikit usaha sector jasa yang merajai pasar terhadap produk sejenis karena memang perusahaan tersebut mampu membuktikan produknya lebih unggul dibanding dengan produk lain, namun tidak sedikit juga yang baru muncul bisa tenggelam lagi karena ketidakmampuan meraih pasar. Dari contoh sektor jasa yang ditawarkan adalah bidang pendidikan yang merupakan kebutuhan primer dalam kehidupan modern.

Pendidikan tentunya akan mencetak Sumber Daya Manusia yang berkualitas baik dari segi spritual, intelegensi dan skill dan pendidikan merupakan proses mencetak generasi penerus bangsa. Apabila output dari proses pendidikan ini gagal maka sulit dibayangkan bagaimana dapat mencapai kemajuan.

Seperti banyak diketahui bahwa semakin hari semakin banyak bermunculan lembaga pendidikan baik formal maupun non formal dengan berbagai jenjang dan program studi yang ditawarkan sehingga persaingan semakin ketat terutama dari kalangan lembaga pendidikan swasta. Dalam hal ini pendidikan setelah Sekolah Menengah Atas (SMA) yaitu jenjang Perguruan Tinggi Swasta (PTS). Mereka berlomba lomba meraih jumlah mahasiswa sebanyak mungkin. Berbagai penawaran yang menarik dari fasilitas sampai kelulusan siap kerja. Oleh karena itu caoln mahasiswa juga harus jeli dalam memutuskan untuk menempuh kuliah di 
Perguruan Tinggi yang mana karena hal ini juga akan berpengaruh tehadap masa depan calon mahasiswa tersebut.

Salah satu PTS di lingkungan Surakarta adalah Sekolah Tinggi Ilmu Ekonomi AAS (STIE AAS) yaitu Perguruan Tinggi swasta yang sudah mengalami pasang surut dalam perkembangannya selama kurun waktu 20 tahunan. Melihat kondisi dalam dua tahun terakhir ini perlu kiranya STIE AAS mengevaluasi dan sekaligus menganalisis faktor faktor yang mempengaruhi keputusan calon mahasiwa menempuh Pendidikan STIE AAS. Ditinjau dari strategi Marketing Mix Produk yang ditawarkan STIE AAS dalam hal ini adalah Program studi D3 akuntansi dan Perpajakan serta S1 Akuntansi dan Ekonomi Islam. Harga yang ditawarkan kepada calon mahasiswa adalah pembayaran SPP sebulan sangat terjangkau, saluran distribusi langsung dan promosi dengan media cetak, elektronik dan personal selling.

\section{METODE PENELITIAN}

\section{Jenis Penelitian}

Jenis penelitian yang digunakan adalah deskriptif kualitatif dan deskriptif kuantitatif. Untuk mendeskripsikan jawaban responden tentang faktor yang mempengaruhi keputusan mahasiswa menempuh kuliah di STIE AAS sedangkan untuk membuktikan hipotesis penelitian tentang ada tidaknya pengaruh faktor faktor terhadap keputusan mahasiswa menempuh kuliah di STIE AAS digunakanan analisis Regresi Berganda.

\section{Populasi dan Sampel}

Lokasi Penelitian dilakukan di Sekolah Tingg Ilmu Ekonomi AAS yang berlokasi di Jalan slamet Riyadi 361 Windan Makamhaji Kartasura Obyek Penelitian adalah Mahasiswa baru tahun akademik 2015/2016 yang mempunyai populasi sejumlah orang. Sedang sampel yang diambil untuk penelitian ini berjumlah 80 orang.

\section{Metode Pengumpulan data}

Dalam penelitian ini terdiri dari data primer, yaitu data yang berasal dari sumber utama yaitu Mahasiswa STIE AAS tahun akademik 2015/2016 sebagai responden . Selain itu juga digunakan data sekunder, yaitu merupakan data yang diperoleh dengan proses pengolah lebih lanjut. Sedangkan teknik pengumpulan data dalam penelitian ini dengan cara Kuesioner. Kuesioner yaitu penyebaran angket kuesioner tertutup berupa daftar pertanyaan mengenai masalah yang akan diteliti yang ditujukan kepada mahasiswa yang menjadi sampel penelitian. Daftar berisi pertanyaanpertanyaan tentang pokok permasalahan yang diteliti.

\section{Instrumen Penelitian}

Instrumen yang digunakan dalam penelitian ini adalah skala interval atau skala yang berjenjang. Untuk penetuan bobot atau skor tentang variable variable yang mempengaruhi produktivitas. Dalam penelitian ini digunakan metode skla likert.

Sedangkan untuk menilai valid tidaknya kuesioner dan reliabel tidaknya kuesioner digunakan uji validitas dan uji realibilitas. 


\section{Metode analisa data}

1. Uji Instrumen

a. Uji Validitas

Analisis validitas merupakan analisa yang dilakukan untuk mengukur apakah instrumen yang digunakan dalam penelitian benar-benar mampu mewakili semua aspek yang dianggap sebagai kerangka konsep. Pengujian validitas menggunakan uji korelasi product moment Pearson dengan bantuan Program SPSS. Instrumen dikatakan valid jika angka $\mathrm{r}$ hitung $>\mathrm{r}$ tabel.

b. Uji Reliabilitas

$$
\text { Uji Reliabilitas }
$$
digunakan untuk mengukur $Y=\alpha+\beta_{1} X_{1}+\beta_{2} X_{2}+\beta_{3} X_{3}+\beta_{4}$ $\mathrm{X}_{4}+\beta_{5} \mathrm{X}_{5}+\beta_{6} \mathrm{X}_{6+\mathrm{e}}$

Keterangan:

$\mathrm{Y}=$ Keputusan mahasiswa

$\alpha=$ Konstanta

$\mathrm{X}_{1} \quad=$ Program studi

$\mathrm{X}_{2} \quad=$ Biaya perkuliahan

$\mathrm{X}_{3} \quad=$ Saluran distribusi

3. Uji Hipotesis

a. Uji t

Uji t ini digunakan untuk menguji pengaruh masingmasing variabel independen (program studi, biaya perkuliahan, saluran distribusi, media cetak, media elektronik dan personal selling) terhadap variabel dependen (keputusan bahwa instrumen peneltian bebas dari kesalahan persepsi sehingga menghasilkan hasil yang konsisten dan dapat digunakan pada kondisi yang berbeda-beda. Pengujian reliabilitas menggunakan Cronbach alpha dengan program SPSS. Dikatakan reliabel jika nilai Cronbach alpha > 0,6 Rumus koefisien alpha: (Umar ,2003:90).

2. Analisis Regresi Berganda

Analisa yang akan dilakukan dalam penelitian ini adalah analisa regresi linear berganda dengan rumus sebagai berikut:

$\mathrm{X} 4=$ Media cetak

X5 = Media elektronik

$\mathrm{X} 6=$ Personal selling

$\beta_{1} \ldots \beta_{6}=$ Koefisien variabel independen $\mathrm{X}_{1} \ldots \mathrm{X}_{6}$

e $\quad=$ Error

mahasiswa). Adapun rumus yang digunakan adalah sebagai berikut:

1) Menentukan komposisi hipotesis

Ho : $\beta_{\mathrm{i}}=0$, Tidak ada pengaruh yang signifikan antara program studi, biaya perkuliahan, saluran distribusi, media cetak, 
media elektronik dan personal selling terhadap keputusan mahasiswa secara individual

Ha $: \beta_{\mathrm{i}} \neq 0$, Ada pengaruh yang signifikan antaraprogram studi, biaya perkuliahan, saluran distribusi, media cetak, media elektronik dan personal selling terhadap keputusan mahasiswa secara individual

2) Menentukan level signifikan $\alpha=5 \%$

3) Mencari thitung

Untuk mengetahui diterima atau ditolaknya Ho, maka hasil perhitungan signifikansi ( nilai sig) dibandingkan dengan level

$$
\text { Ho : } \beta_{1}=\beta_{2}=\beta_{3}=0 \text {, }
$$

Tidak ada pengaruh yang signifikan antara secara bersama sama

Ha : $\beta_{1} \neq \beta_{2} \neq \beta_{3} \neq 0$,

Ada

pengaruh

yang signifikan

antara

program

studi, biaya

perkuliahan, saluran distribusi, of significant 0,05. Apabila nilai sig < 0,05, maka Ho ditolak, yang berarti ada pengaruh yang signifikan variabel independen terhadap variabel dependen dan sebaliknya apabila nilai sig > 0,05, berarti terdapat pengaruh tidak signifikan variabel independen terhadap variabel dependen

b. Uji F

Uji ini dilakukan dengan program SPSS. Uji ini digunakan untuk menguji keberartian koefisien regresi secara bersama - sama / serentak. Adapun langkah langkah pengujiannya adalah :

1) Menentukan komposisi hipotesis

media cetak , media elektronik dan personal selling terhadap keputusan mahasiswa secara bersama sama

2) Menentukan level of signifikan $\alpha=5$

3) Mencari F hitung MSR

Rumus : $\mathrm{F}=$

(Widayat, 2004: 179)

MSE 
MSR = Mean Square

\section{Residual}

Untuk mengetahui diterima atau ditolaknya Ho, maka hasil perhitungan signifikansi ( nilai sig) dibandingkan dengan level of significant 0,05. Apabila nilai sig < 0,05, maka Ho ditolak, yang berarti ada pengaruh yang signifikan variabel independen terhadap variabel dependen dan sebaliknya apabila nilai sig > 0,05 , berarti terdapat pengaruh tidak signifikan variabel independen terhadap variabel dependen.

c. $\mathrm{Uji} \mathrm{R}^{2}$

Uji ini dilakukan untuk mengetahui berapa besar pengaruh variabel independen terhadap variabel dependen. Rumus yang digunakan adalah:

$\beta^{2} \sum x_{i}^{2}$

$$
\begin{aligned}
& \mathrm{R}^{2}= \\
& \text { (Suharyadi dan Purwanto, } \\
& \text { 2004) }
\end{aligned}
$$

$\sum \mathrm{y}_{\mathrm{i}}^{2}$

Dimana :

$\mathrm{R}^{2} \quad=$ Koefisien Determinasi

$\beta=$ beta

$\Sigma \mathrm{xi}^{2}=$ jumlah kuadrat nilai $\mathrm{x}$

$\Sigma \mathrm{Yi}^{2}=$ jumlah kuadrat nilai

\section{PEMBAHASAN}

\section{Uji Instrumen}

a. Uji Validitas Instrumen

MSE = Mean Square error

Uji validitas

dimaksudkan untuk mengetahui sahih tidaknya butir pertanyaan yang diajukan. Suatu angket dikatakan valid (sah) jika pertanyaan pada suatu angket mampu untuk mengungkapkan sesuatu yang akan diukur oleh angket tersebut. Penentuan validitas menggunakan pengukuran berdasar pada koefisien korelasi product moment.

Jika nilai $r$ hitung positif dan lebih besar dari $r$ tabel, maka butir yang diuji dinyatakan valid. Tetapi jika nilai $r$ hitung lebih kecil dari $r$ tabel atau bertanda negatif, maka butir yang diuji dinyatakan tidak valid, dan harus dikeluarkan dari proses analisis berikutnya.

1) Variabel Program Studi (X1)

Berdasarkan hasil uji Validitas dengan SPSS, diketahui bahwa ke-5 item pernyataan variabel Program studi (X1) dinyatakan valid. Hal ini dikarenakan ke-5 item pernyataan mempunyai $\mathrm{r}$ hitung $>\mathrm{r}$ tabel $(\mathrm{n}=$ $80, \alpha=0,05>0,220)$; maka ke-5 item pernyataan variabel Program studi (X1) valid atau sahih. Jadi ke5 item pernyataan variable program studi (X1) dapat dilanjutkan uji reliabilitasnya.

2) Variabel Biaya Perkuliahan (X2) 
Berdasarkan hasil Uji Validitas dengan SPSS, diketahui bahwa ke-5 item pernyataan variabel biaya perkuliahan (X2) dinyatakan valid. Hal ini dikarenakan ke-5 item pernyataan mempunyai $r$ hitung $>r$ tabel $(\mathrm{n}=80, \alpha=0,05>$ 0,220) ; maka ke-5 item pernyataan variable biaya perkuliahan (X2) valid atau sahih. Jadi ke-5 item pernyataan variabel biaya perkuliahan (X2) dapat dilanjutkan uji reliabilitasnya.

3) Variabel Lokasi Kampus (X3)

Berdasarkan hasil Uji Validitas dengan SPSS, diketahui bahwa ke-5 item pernyataan variabel lokasi kampus (X3) dinyatakan valid. Hal ini dikarenakan ke-5 item pernyataan mempunyai $\mathrm{r}$ hitung $>\mathrm{r}$ tabel $(\mathrm{n}=80, \alpha=0,05>$ 0,220); maka ke-5 item pernyataan variable lokasi kampus (X3) valid atau sahih. Jadi ke-5 item pernyataan variabel lokasi kampus (X3) dapat dilanjutkan uji reliabilitasnya.

4) Variabel Media Cetak (X4)
Berdasarkan hasil Uji Validitas dengan SPSS, diketahui bahwa ke-5 item pernyataan variable media cetak (X4) dinyatakan valid. Hal ini dikarenakan ke-5 item pernyataan mempunyai $\mathrm{r}$ hitung $>\mathrm{r}$ tabel $(\mathrm{n}=80, \alpha$ $=0,05>0,220)$; maka ke-5 item pernyataan variabel media cetak (X4) valid atau sahih. Jadi ke-5 item pernyataan variabel media cetak (X4) dapat dilanjutkan uji reliabilitasnya.

5) Variabel Media Elektronik (X5)

Berdasarkan hasil Uji Validitas dengan SPSS, diketahui bahwa ke-5 item pernyataan variable media elektronik (X5) dinyatakan valid. Hal ini dikarenakan ke-5 item pernyataan mempunyai $r$ hitung $>r$ tabel $(\mathrm{n}=80, \alpha=0,05>$ 0,220); maka ke-5 item pernyataan variable media elektronik (X5) valid atau sahih. Jadi ke-5 item pernyataan variabel media elektronik (X5) dapat dilanjutkan uji reliabilitas

6) Variabel Personal Selling (X6)

Berdasarkan hasil Uji Validitas dengan SPSS, diketahui bahwa ke-5 item pernyataan variabel personal 
selling (X6) dinyatakan valid. Hal ini dikarenakan ke-5 item pernyataan mempunyai $\mathrm{r}$ hitung $>\mathrm{r}$ tabel $(\mathrm{n}=80, \alpha=0,05>$ 0,220); maka ke-5 item pernyataan variabel personal selling (X6) valid atau sahih. Jadi ke-5 item pernyataan variabel personal selling (X6) dapat dilanjutkan uji reliabilitasnya

7) Variabel Keputusan Mahasiswa menempuh Kuliah (Y)

Berdasarkan hasil Uji Validitas dengan SPSS, diketahui bahwa ke-5 item pernyataan variabel keputusan mahasiswa (Y) dinyatakan valid. Hal ini dikarenakan ke-5 item pernyataan mempunyai $r$ hitung $>r$ tabel $(\mathrm{n}=80, \alpha=$ $0,05>0,220)$; maka ke-5 item pernyataan variabel keputusan mahasiswa valid atau sahih. Jadi ke-5 item pernyataan variabel keputusan mahasiswa (Y) dapat dilanjutkan uji reliabilitasnya

\section{a. Uji Reliabilitas.}

Hasil pengujian reliabilitas instrumen variabel diperoleh hasil seperti yang terlihat pada tabel sebagai berikut: Program studi $\left(\mathrm{X}_{1}\right)$, Biaya perkuliahan (X2), Lokasi Kampus (X3), Media Cetak (X4), Media Elektronik( X5), personal selling (X6) dan Keputusan Mahasiswa ( Y )

Tabel 5.12

Rangkuman Hasil Uji realibilitas

\begin{tabular}{|l|c|c|c|}
\hline \multicolumn{1}{|c|}{ Variabel } & Nilai Cronbach $\alpha$ & Nilai Batas & Keputusan \\
\hline Program studi (X1) & 0.744 & 0,6 & Reliabel \\
\hline Biaya Perkuliahan (X2) & 0.844 & 0,6 & Reliabel \\
\hline Lokasi Kampus (X3) & 0.710 & 0,6 & Reliabel \\
\hline Media cetak (X4) & 0.455 & 0,6 & Reliabel \\
\hline Media elekktronik (X5) & 0.766 & 0,6 & Reliabel \\
\hline Personal selling (X6) & 0.656 & 0,6 & Reliabel \\
\hline Keputusan Mahasiswa(Y) & 0.694 & 0,6 & Reliabel \\
\hline
\end{tabular}

Sumber : data instrumen diolah, 2016

\section{Uji Hipotesis}

Pengujian hipotesis dalam penelitian ini menggunakan analisis 
regresi, uji t dan uji F. Analisis regresi adalah analisis untuk mengetahui pengaruh Program studi $\left(\mathrm{X}_{1}\right)$, Biaya perkuliahan (X2), Lokasi Kampus (X3), Media Cetak (X4), Media Elektronik( X5) dan personal selling (X6) terhadap Keputusan Mahasiswa (Y). Berdasarkan hasil regresi dari data primer yang diolah dengan menggunakan program SPSS 19 for windows diperoleh hasil sebagai

\section{a. Analisis Regresi Linier Berganda}

Dari hasil perhitungan dengan menggunakan program SPSS Versi 19 for windows, terhadap variabel-variabel yang disebutkan diatas maka dapat diketahui pada hasil regresi seperti yang tersaji pada tabel sebagai berikut:

Tabel 5.13

\section{Hasil Analisis Koefisien Regresi}

\begin{tabular}{|l|r|r|r|r|r|}
\hline \multirow{2}{*}{ Model } & \multicolumn{2}{|c|}{$\begin{array}{c}\text { Unstandardized } \\
\text { Coefficients }\end{array}$} & $\begin{array}{l}\text { Standardized } \\
\text { Coefficients }\end{array}$ & \multicolumn{1}{c|}{$\mathrm{T}$} & Sig. \\
\cline { 2 - 6 } & \multicolumn{1}{|c|}{$\mathrm{B}$} & $\begin{array}{c}\text { Std. } \\
\text { Error }\end{array}$ & \multicolumn{1}{c|}{ Beta } & & \\
\hline \multicolumn{1}{|c|}{ Constant } & 6.714 & 3.133 & & 2.143 & .035 \\
\hline $\begin{array}{l}\text { Program studi } \\
\text { (X1) }\end{array}$ & -.079 & .111 & -.104 & -.707 & .482 \\
\hline $\begin{array}{l}\text { Biaya Perkuliahan } \\
\text { (X2) }\end{array}$ & .088 & .090 & .120 & .981 & .330 \\
\hline $\begin{array}{l}\text { Lokasi Kampus } \\
\text { (X3) }\end{array}$ & .088 & .105 & .119 & .834 & .407 \\
\hline Media cetak (X4) & .243 & .131 & .225 & 1.848 & .069 \\
\hline $\begin{array}{l}\text { Media elekktronik } \\
\text { (X5) }\end{array}$ & .013 & .104 & .019 & .127 & .900 \\
\hline $\begin{array}{l}\text { Personal selling } \\
\text { (X6) }\end{array}$ & .179 & .100 & .220 & 1.794 & .077 \\
\hline
\end{tabular}

Sumber: data pokok diolah, 2016

Berdasarkan hasil analisis seperti yang terlihat pada tabel diatas dapat dibuat persamaan regresinya sebagai berikut:

$$
\begin{aligned}
\mathrm{Y}= & 6.714-0,079 \mathrm{X} 1+0,088 \mathrm{X} 2+0.088 \mathrm{X} 3+0.243 \mathrm{X} 4+0.013 \mathrm{X} 5+0.179 \mathrm{X} 6 \\
& 0.035(0.482) \quad(0.330) \quad(0.407) \quad(0.069)
\end{aligned}
$$


Dari persamaan regresi diatas diketahui bahwa nilai koefisien regresi adalah 5 variabel bebas bertanda positif terhadap variabel terikat (Keputusan mahasiswa ). Ini berarti variabel Biaya perkuliahan (X2), Lokasi Kampus (X3), Media Cetak (X4), Media Elektronik( X5) dan personal selling (X6) berpengaruh positif terhadap Keputusan Mahasiswa (Y). Sedangkan variabel Program studi (X1) tidak berpengaruh positif terhadap Keputusan Mahasiwa ( Y ) b. Uji Pengaruh Serempak (Uji F)

Uji F merupakan perhitungan untuk mengetahui apakah variabel independen yang terdiri dari variabelvariabel Program studi $\left(\mathrm{X}_{1}\right)$, Biaya perkuliahan (X2), Lokasi Kampus (X3), Media Cetak (X4), Media Elektronik( X5) dan personal selling (X6) secara simultan atau serempak mempunyai pengaruh yang signifikan terhadap variabel dependen dalam hal ini adalah Keputusan Mahasiswa (Y). Dari analisis diperoleh hasil seperti pada tabel sebagai berikut.

Tabel 5.14

Hasil Uji F

ANOVAb

\begin{tabular}{|c|c|c|c|c|c|c|}
\hline \multicolumn{2}{|c|}{ Model } & $\begin{array}{l}\text { Sum of } \\
\text { Squares }\end{array}$ & Df & $\begin{array}{l}\text { Mean } \\
\text { Square }\end{array}$ & $\mathrm{F}$ & Sig. \\
\hline \multirow[t]{3}{*}{1} & Regression & 66.717 & 6 & 11.120 & 3.273 & $.007^{\mathrm{a}}$ \\
\hline & Residual & $\begin{array}{r}247 . \\
970\end{array}$ & 73 & 3.397 & & \\
\hline & Total & 314.688 & 79 & & & \\
\hline
\end{tabular}

a. Predictors: (Constant), X6, X4, X5, X2, X3, X1

$\begin{array}{llr}\text { Hasil uji } & \text { secara } \\ \text { serempak }(\mathrm{Uji} & \mathrm{F}) & \text { diketahui } \\ \text { besarnya nilai } F & =3.273 \\ \text { signifikansi } 0,007 & <0,05 .\end{array}$

Sehingga dapat disimpulkan secara bersama-sama variabel bebas mempengaruhi Keputusan mahasiswa

\section{c. Uji Pengaruh Parsial ( Uji t )}

Berdasarkan hasil pengujian yang telah dilakukan seperti pada tabel 5.13 Persamaan 
dapat dijelaskan hal - hal berikut:

1) Pengaruh program studi terhadap Keputusan mahasiswa Hasil pengujian regresi yang dilakukan menunjukkan untuk variabel program studi mempunyai nilai signifikansi $0.482>0,05$ artinya variabel program studi tidak ada pengaruh signifikan terhadap Keputusan mahasiswa. Kesimpulan dari pengujian ini Hipotesis tidak terbukti.

2). Pengaruh biaya perkuliahan terhadap Keputusan mahasiswa

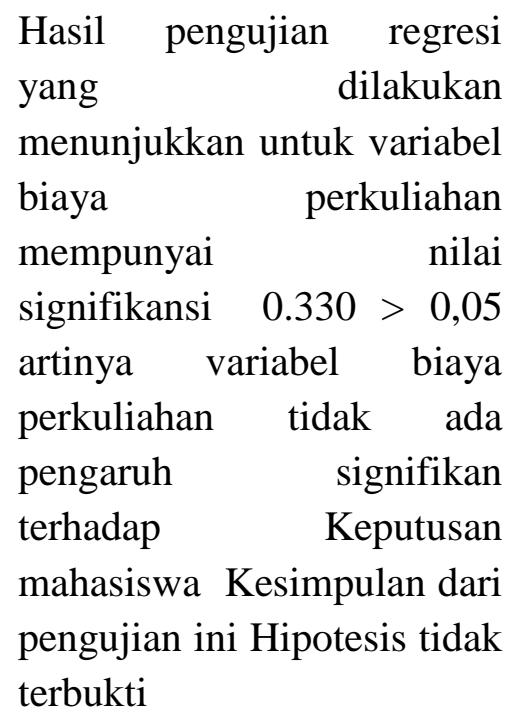

3). Pengaruh Lokasi kampus terhadap Keputusan mahasiswa.

Hasil pengujian regresi yang dilakukan menunjukkan untuk variabel lokasi kampus mempunyai nilai signifikansi $0.407>0,05$, artinya variabel lokasi kampus tidak ada pengaruh signifikan terhadap Keputusan mahasiswa,
Kesimpulan dari pengujian ini Hipotesis tidak terbukti.

4). Pengaruh media cetak terhadap Keputusan mahasiswa.

Hasil pengujian regresi yang dilakukan menunjukkan untuk variabel lokasi kampus mempunyai nilai signifikansi $0.066>0,05$, artinya variabel media cetak tidak ada pengaruh signifikan terhadap Keputusan mahasiswa, Kesimpulan dari pengujian ini Hipotesis tidak terbukti

5). Pengaruh media elektronik terhadap Keputusan mahasiswa

Hasil pengujian regresi yang dilakukan menunjukkan untuk variabel media cetak mempunyai nilai signifikansi $0.900>0,05$, artinya variabel media elektronik tidak ada pengaruh signifikan terhadap Keputusan mahasiswa. Kesimpulan dari pengujian ini Hipotesis tidak terbukti.

6). Pengaruh personal selling terhadap Keputusan mahasiswa

Hasil pengujian regresi yang dilakukan menunjukkan untuk variabel personal selling mempunyai nilai signifikansi $0,077>0,05$, artinya variabel personal selling tidak ada pengaruh signifikan terhadap Keputusan mahasiswa Kesimpulan dari pengujian ini Hipotesis tidak terbukti 


\section{d. Uji $\mathbf{R}^{\mathbf{2}}$ (Koefisien Determinasi)}

Koefisien determinasi ini

untuk mengetahui besarnya sumbangan pengaruh variabel bebas (Program studi, Biaya perkuliahan, Lokasi Kampus, Media cetak, Media elektronik dan Personal selling ) terhadap variabel dependen (Keputusan Mahasiswa menempuh kuliah di STIE AAS) yang ditunjukkan dengan besarnya $\mathrm{R}^{2}$. Hasil perhitungan koefisien determinasi dapat dilihat di tabel berikut ini.

Tabel 5.15

Hasil Koefisien Determinasi $\left(\mathbf{R}^{\mathbf{2}}\right)$

Model Summary ${ }^{\text {b }}$

\begin{tabular}{|l|r|r|r|r|r|}
\hline Model & $\mathrm{R}$ & R Square & $\begin{array}{c}\text { Adjusted R } \\
\text { Square }\end{array}$ & $\begin{array}{c}\text { Std. Error of } \\
\text { the Estimate }\end{array}$ & $\begin{array}{l}\text { Durbin- } \\
\text { Watson }\end{array}$ \\
\hline 1 & $.460^{\mathrm{a}}$ & .212 & .147 & 1.84305 & 1.710 \\
\hline
\end{tabular}

a. Predictors: (Constant), X6, X4, X5, X2, X3, X1

b. Dependent Variable: Y

Berdasarkan hasil analisis seperti yang tersaji pada Tabel diatas dapat diketahui bahwa nilai koefisien determinasi (Adjusted $R$ Square) sebesar 0,147 atau 14,7 $\%$. Hal ini berarti variabel Program studi $\left(\mathrm{X}_{1}\right)$, Biaya perkuliahan (X2), Lokasi Kampus (X3), Media Cetak (X4), Media Elektronik( X5) dan personal selling (X6) memberikan konstribusinya sebesar 14,7 \% terhadap Keputusan Mahasiswa Sedangkan sisanya sebesar 85,3 $\%$ dipengaruhi oleh variabel lain diluar penelitian ini, seperti Faktor Pribadi , Faktor Lingkungan Eksternal, Faktor Sosial, Faktor Psikologis juga factor-faktor lainnya.

\section{SIMPULAN}

Berdasarkan hasil analisis data dan pengujian hipotesis yang telah dilakukan maka dapat ditarik kesimpulan sebagai berikut:

Berdasarkan hasil analisis data dan pengujian hipotesis yang telah dilakukan maka dapat ditarik kesimpulan sebagai berikut:

1. Program studi (produk) tidak mempunyai pengaruh yang signifikan terhadap Keputusan mahasiswa menempuh kuliah di STIE AAS

2. Biaya perkuliahan (Harga) tidak mempunyai pengaruh yang signifikan terhadap Keputusan mahasiswa menempuh kuliah di STIE AAS AAS 
3. Lokasi kampus (Distribusi) tidak mempunyai pengaruh yang signifikan terhadap Keputusan mahasiswa menempuh kuliah di STIE AAS

4. Promosi dengan media cetak tidak mempunyai pengaruh yang signifikan terhadap Keputusan mahasiswa menempuh kuliah di STIE AAS

5. Promosi dengan media elektronik tidak mempunyai pengaruh yang signifikan terhadap Keputusan mahasiswa menempuh kuliah di STIE AAS

6. Promosi dengan personal selling tidak mempunyai pengaruh yang signifikan terhadap Keputusan mahasiswa menempuh kuliah di STIE AAS

7. Terdapat pengaruh yang signifikan secara simultan antara variabel independen yang terdiri dari variabel variabel marketing mix yaitu : Program studi, Biaya perkuliahan, Lokasi Kampus, Media Cetak, Media Elektronik dan personal selling terhadap Keputusan mahasiswa menempuh kuliah di STIE AAS.

\section{DAFTAR PUSTAKA}

Abdurachman, Ujianto, 2004, Jurnal Manajemen \& Kewirausahaan Vol. 6, No. 1, Maret 2004: 34 - 53 Analisis Faktor-Faktor yang Menimbulkan Kecenderungan Minat Beli Konsumen Sarung (Studi Perilaku Konsumen Sarung di Jawa Timur), Staf Pengajar
Fakultas Ekonomi,Universitas 17 Agustus 1945 Surabaya.

Arikunto, Suharsini (2002) Dasar-dasar Pemasaran, Penerbit Pretallindo, Jakarta

Buchori, Alma (2004). Manajemen Pemasaran dan Pemasaran Jasa. Penerbit Bandung Alfabeta

Buchori, Alma (2008). Manajemen Pemasaran dan Pemasaran Jasa. Penerbit Bandung, Alfabeta

Fandy, Tjiptono dan Gregorius (2005) Service, Quality satisfaction, Yogyakarta andi offset

Fathorrahman (2009). Jurnal Ilmiah Bisnis dan ekonomi Vol. 4, No, 1, Desember 2009: 66 - 86 Faktor faktor yang dipertimbangkan konsumen dalam melakukan pembelian sepeda motor merk Honda di kecamatan Pademawu Kabupaten pamekasan.

Kotler, Philip; Armstrong, Garry, 2008. Prinsip-prinsip Pemasaran, Jilid 1,. Jakarta Erlangga

Kotler, Phillip (2010), Kevin Lane Keller, Manajemen Pemasaran, jilid 2 Edisi 13 Jakarta Penerbit Indeks

Kotler Phillip, Keller Kevin Lane (2004). Marketing Associate diterjemahkan oleh Bob Sabran, 2009. Jakarta Gramedia Pustaka Utama

Much. Angsori (2010). Pengaruh Strategi Marketinf Mix terhadap LLoyalitas Pelanggan PT Pos Indonesia Kantor Pos Wonogiri. STIE Atma Bhakti Surakarta 
Ridwan, Adun Rusyana (2011) Cara mudah belajar SPSS 17 dan Aplikasi Statisik Penelitian, Bandung Penerbit Alfabeta

Singarimbun, Masri, dan Sofian Efendi,(2006). Metode Penelitian Survei, Jakarta, Penerbit LP3ES

Sri Hadiati, Sarwi Ruci (2008), Analisis Kinerja Kualitas Pelayanan terhadap Kepuasan Pelanggan, Journal costumer satisfaction, Mei 14

Sugiyono (2007) Metode Penelitian Bisnis, Bandung, CV.Alfabeta

Suharyadi dan Purwanto, Statistika : Untuk ekonomi dan euangan modern, edisi 2, Yogyakarta Salemba empat

Swastha, Bhasu DH dan Hani Handoko(1987), Manajemen Pemasaran, Cetakan ke 2, Penerbit Liberty

Tjiptono, Fandy, 2005.Pemasaran Jasa, Malang. , Penerbit Bayumedia

Umar Husein, 2002, Riset Pemasaran dan perilaku konsumen, Jakarta : Gramedia Pustaka Utama

Widayat (2004) Mtode penelitian Pemasaran ( Aplikasi software SPSS) Malang UMM Press 